\title{
A low psoas muscle volume correlates with a longer hospitalization after radical cystectomy
}

\author{
Yoko Saitoh-Maeda', Takashi Kawahara ${ }^{1,2^{*}} \mathbb{D}^{1}$, Yasuhide Miyoshi ${ }^{1}$, Sohgo Tsutsumi ${ }^{1}$, Daiji Takamoto', \\ Kota Shimokihara', Yuutaro Hayashi ${ }^{1}$, Taku Mochizuki ${ }^{1}$, Mari Ohtaka ${ }^{1}$, Manami Nakamura ${ }^{1}$, Yusuke Hattori ${ }^{1}$, \\ Jun-ichi Teranishi', Yasushi Yumura', Kimito Osaka², Hiroki Ito², Kazuhide Makiyama², Noboru Nakaigawa², \\ Masahiro $\mathrm{Yao}^{2}$ and Hiroji Uemura ${ }^{1}$
}

\begin{abstract}
Background: Recently, sarcopenia has been reported as a new predictor for patient outcomes or likelihood of post-operative complications. The purpose of this study was to evaluate the association of the psoas muscle volume with the length of hospitalization among patients undergoing radical cystectomy.
\end{abstract}

Methods: A total of 63 (80.8\%) male patients and 15 (19.2\%) female patients who underwent radical cystectomy for their bladder cancer in our institution from 2000 to 2015 were analyzed. The psoas muscle index (PMI) was calculated by normalizing the psoas muscle area calculated using axial computed tomography at the level of the umbilicus $\left(\mathrm{cm}^{2}\right)$ by the square of the body height $\left(\mathrm{m}^{2}\right)$. Longer hospitalization was defined as hospitalization exceeding 30 days after surgery.

Results: The median PMls (mean \pm standard deviation) were $391(394 \pm 92.1)$ and $271(278 \pm 92.6) \mathrm{cm}^{2} / \mathrm{m}^{2}$ in men and women, respectively. Thus, the PMls of male patients were significantly larger than those of females $(p<0.001)$. Based on the differences in gender, we analyzed 63 male patients for a further analysis. In male patients, those hospitalized longer showed a significantly smaller PMI than those normally discharged (377 \pm 93.1 vs. $425 \pm 83.4 ; p=0.04)$. Similarly, male patients with a small PMI $(<400)$ had a significantly worse overall survival $(p=0.02)$ than those with a large PMI $(\geq 400)$.

Conclusions: The presence of sarcopenia was found to be associated with significantly longer hospitalization after radical cystectomy in male patients. Furthermore, in men, a PMl $<400$ may suggest a significantly worse prognosis.

Keywords: Bladder cancer, Radical cystectomy, Sarcopenia, Psoas muscle

\section{Background}

For locally advanced bladder cancer, radical cystectomy is still the gold standard therapy $[1,2]$. However, despite its effectiveness, the perioperative complication rate is reported to be around 30\%, and the 30- and 90-day post-operative mortality rates are $3.2 \%$ and $5.2 \%$,

\footnotetext{
*Correspondence: takashi_tk2001@yahoo.co.jp

'Departments of Urology and Renal Transplantation, Yokohama City University Medical Center, 4-57 Urafune-cho, Minami-ku, Yokohama, Kanagawa 2320024, Japan

${ }^{2}$ Department of Urology, Yokohama City University Graduate School of Medicine, Yokohama, Japan

respectively [1-3]. The indication for radical cystectomy is usually considered based on the patient's age, complications, and performance status $[4,5]$. Recently, sarcopenia was reported as a new predictor for the prognosis or risk of post-operative complications $[1,6,7]$.

Sarcopenia is the age-related loss of skeletal muscle mass [8]. Previous studies have defined the sum of the muscle masses of the four limbs as the appendicular skeletal mass in order to calculate the psoas muscle index (PMI) $[9,10]$. A correlation between sarcopenia and oncologic outcomes has been reported in malignant melanoma, breast cancer, and hepatocellular carcinoma 
[11-14]. In patients with bladder cancer, several studies have suggested that sarcopenia correlates with a worse prognosis than in those without sarcopenia [1, 7]. However, whether or not the PMI easily determined using the one-side psoas volume in non-contrast computed tomography $(\mathrm{CT})$ precisely predicts post-operative complications as well as the long-term oncologic outcomes in patients undergoing radical cystectomy remains controversial.

We therefore explored the value of sarcopenia in bladder cancer patients who underwent radical cystectomy.

\section{Methods}

\section{Patients}

A total of 78 patients (63 males and 15 females) underwent radical cystectomy for bladder cancer at Yokohama City University Medical Center (Yokohama, Japan) from 2000 to 2015. All of the patients were Japanese. The institutional review board of Yokohama City University Medical Center approved this study [D1507018]. The patients were followed up every three months for two years after cystectomy and every six months thereafter using CT.

\section{Clinical assessments}

The volume and area of the psoas muscle were calculated using axial $\mathrm{CT}$ at the level of the umbilicus before radical cystectomy. The PMI $\left(\mathrm{cm}^{2} / \mathrm{m}^{2}\right)$ was calculated by normalizing the psoas muscle area $\left(\mathrm{cm}^{2}\right)$ by the square of the body height $\left(\mathrm{m}^{2}\right)$.

Longer hospitalization was defined as hospitalization exceeding 30 days after surgery. Based on observed differences in gender, we analyzed the 63 male patients in a further analysis. The overall survival (OS) was compared between the high- $(\geq 400)$ and low- $(<400)$ PMI groups. The patients' perioperative complications were assessed and scored according to the modified Clavien grading system.

\section{Statistical analysis}

The patients' characteristics and preoperative factors were analyzed using the Mann-Whitney $U$ and chisquared tests. The Kaplan-Meier product limit estimator was used to estimate the OS. The survival duration was defined as the time between radical cystectomy and death. The log-rank test was performed for comparison. A $p$ value of $<0.05$ was considered to be statistically significant.

\section{Results}

Patients' characteristics

The median/mean ( \pm standard deviation (SD)) follow-up times in male and female patients after radical cystectomy were 24.8/36.6 ( \pm 30.9) and 25.4/31.5 ( \pm 24.6) months, respectively The median/mean $( \pm \mathrm{SD})$ durations of post-operative hospitalization were 36/39.7 ( \pm 17.4) days in male patients and 37.0/42.1 ( \pm 15.3) days in female patients.

\section{Length of hospitalization vs. psoas muscle volume}

The median/mean $( \pm \mathrm{SD})$ psoas areas of the 63 male and 15 female patients were 1078/1085 ( \pm 254$)$ and 632/ 634 $( \pm 239) \mathrm{cm}^{2}$, respectively, and the PMIs were 391/ $393( \pm 92.1)$ and $271 / 278( \pm 92.6) \mathrm{cm}^{2} / \mathrm{m}^{2}$, respectively. Thus, male patients had a significantly higher PMI than female patients $(p<0.001$, Fig. 1$)$. Among the male patients, those hospitalized longer showed a significantly smaller psoas muscle volume than those normally discharged (Fig. 2). A similar trend was noted among female patients (longer hospitalized group: $763 / 1045 \pm 826 \mathrm{~cm}^{2} / \mathrm{m}^{2}$ vs. control group: $\left.774 / 670 \pm 373 \mathrm{~cm}^{2} / \mathrm{m}^{2}\right)$, but the difference was not statistically significant $(p=0.405)$, possibly due to the small number of female subjects.

\section{Histopathological features}

Histopathological features in male patients, including tumor grade, pathological $\mathrm{T}$ stage, lymph node metastasis, and the presence of concurrent carcinoma in situ (CIS), are summarized in Table 1. The frequencies of clinical $\mathrm{T}$ and $\mathrm{N}$ stage showed no marked differences between the high- and low-PMI groups. In the male, older patients tended to have a lower PMI than the younger patients; however, the difference did not reach statistical significance. The correlation coefficient (R2) was 0.022 .

\section{Correlation of PMI with the OS}

The OS was compared in male patients with high versus low PMI. Kaplan-Meier and log-rank tests revealed that the patients with a high PMI had a significantly better OS than those with a low PMI $(p=0.023$, Fig. 3$)$. The mean survivals were 2889 days

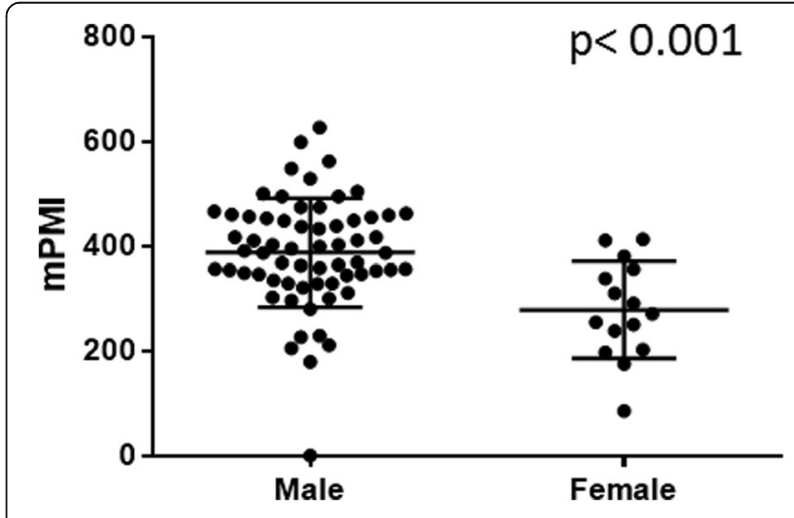

Fig. 1 PMI in male versus female bladder cancer patients undergoing radical cystectomy 


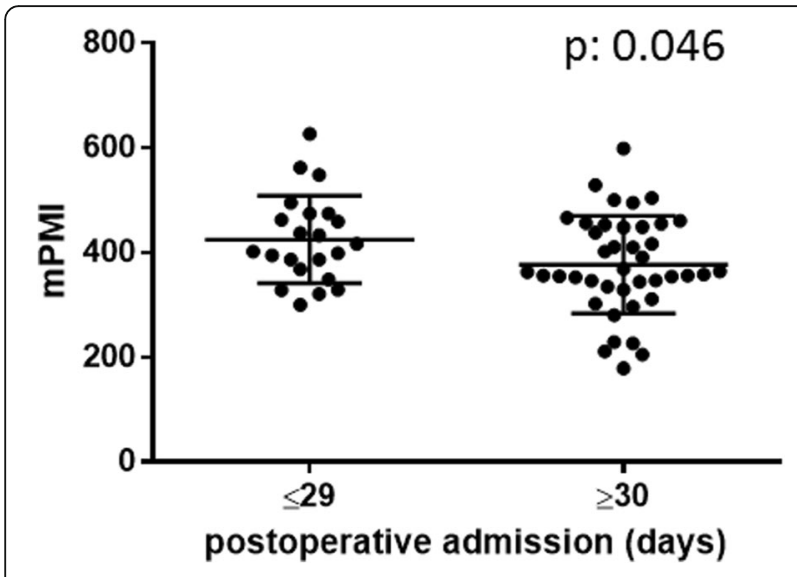

Fig. $2 \mathrm{PMl}$ and duration of postoperative admission in male patients in the high-PMI group and 2009 days in the low-PMI group.

\section{Perioperative complications}

In male patients, the low-PMI group showed a significantly higher rate of complications than the high-PMI group $(82.9 \%$ vs $31.8 \%, p<0.001)$. Furthermore, the patients in the low-PMI group experienced severe complications (Clavien grade $\geq 3,19.5 \%$ ) (Table 2).

\section{Discussion}

Sarcopenia is defined as a low volume of skeletal muscle. Sarcopenic patients show a worse swallowing function and nutritional condition than those without sarcopenia [15]. One study reported that sarcopenic patients had a lower activity of daily life than those without sarcopenia at $\geq 65$ years of age [16]. Recently, sarcopenia has been reported as a predictive factor for postoperative complications and the survival in several cancers. For instance, in patients

Table 1 Patient characteristics and psoas muscle volume in male patients

\begin{tabular}{|c|c|c|c|c|}
\hline & $\begin{array}{l}\text { Total (male only) } \\
(n=63)\end{array}$ & $\begin{array}{l}\mathrm{PMI}<400 \\
(n=34)\end{array}$ & $\begin{array}{l}\mathrm{PMI} \geq 400 \\
(n=29)\end{array}$ & $P$ value \\
\hline \multicolumn{5}{|l|}{ Age } \\
\hline$<65$ years & $30(47.6 \%)$ & $12(35.3 \%)$ & $18(62.1 \%)$ & \multirow[t]{2}{*}{0.062} \\
\hline$\geq 65$ years & $33(52.4 \%)$ & $22(64.7 \%)$ & $11(37.9 \%)$ & \\
\hline \multicolumn{5}{|l|}{ Pathological Tumor Grade } \\
\hline 1 & $1(1.2 \%)$ & $0(0 \%)$ & $1(38.5 \%)$ & \multirow[t]{3}{*}{0.477} \\
\hline 2 & $25(39.7 \%)$ & $13(41.0 \%)$ & $12(46.1 \%)$ & \\
\hline 3 & $32(50 \%)$ & $19(59.4 \%)$ & $13(50 \%)$ & \\
\hline \multicolumn{5}{|l|}{ Pathological T Stage } \\
\hline$\leq \mathrm{pT} 2$ & $46(74.2 \%)$ & $21(63.6 \%)$ & $25(93.1 \%)$ & \multirow[t]{2}{*}{0.047} \\
\hline$\geq \mathrm{pT3}$ & $14(25.8 \%)$ & $12(37.4 \%)$ & $2(6.9 \%)$ & \\
\hline \multicolumn{5}{|l|}{ Lymph Node Metastasis } \\
\hline pNO & $56(88.9 \%)$ & $30(88.2 \%)$ & $26(89.7 \%)$ & \multirow[t]{2}{*}{0.097} \\
\hline $\mathrm{pN}+$ & $7(11.1 \%)$ & $4(11.8 \%)$ & $3(10.3 \%)$ & \\
\hline \multicolumn{5}{|l|}{ Concurrent CIS } \\
\hline Yes & $12(19.0 \%)$ & $5(14.7 \%)$ & $7(24.1 \%)$ & \multirow[t]{2}{*}{0.521} \\
\hline No & $51(81.0 \%)$ & $29(85.3 \%)$ & $22(75.9 \%)$ & \\
\hline \multicolumn{5}{|l|}{ Prognosis } \\
\hline Death & $10(15.9 \%)$ & $8(23.5 \%)$ & $2(6.9 \%)$ & \multirow[t]{2}{*}{0.258} \\
\hline Alive & $53(84.1 \%)$ & $26(76.5 \%)$ & $27(93.1 \%)$ & \\
\hline \multicolumn{5}{|l|}{ Body Height } \\
\hline Median, Mean \pm SD & $166,166 \pm 5.84$ & $166,165 \pm 6.32$ & $167,167 \pm 5.31$ & 0.595 \\
\hline \multicolumn{5}{|l|}{ Psoas area (cm2) } \\
\hline Median, Mean \pm SD & $1078,1085 \pm 255$ & $920,896 \pm 152$ & $1297,1307 \pm 149$ & $<0.001$ \\
\hline \multicolumn{5}{|c|}{ Psoas Muscle Index (cm2/m2) } \\
\hline Median, Mean \pm SD & $391,393 \pm 92.1$ & $347,327 \pm 57.3$ & $347,472 \pm 56.7$ & $<0.001$ \\
\hline
\end{tabular}




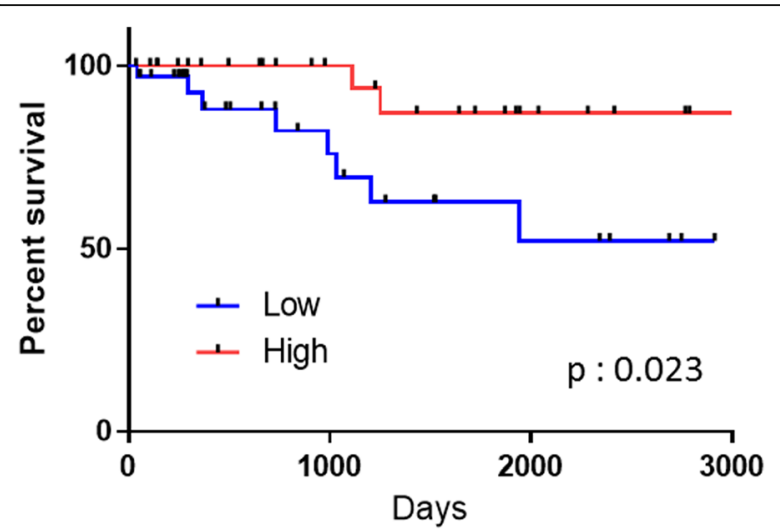

Fig. 3 Overall survival in male patients with high and low PMls

with stage 2 or 3 gastric cancer undergoing gastrectomy, sarcopenia was found to be correlated with higher rates of postoperative complications and a poorer overall and disease-free survival than in those without sarcopenia [17]. Another study found that male sarcopenia patients who underwent pancreatectomy showed a poorer overall survival than those without sarcopenia [18].

Although the detailed mechanism underlying the association between sarcopenia and post-operative complications remains unknown, body frailty is suspected to be involved, as body failure or reduced body durability results in longer admission duration [19]. Sarcopenia develops due to body frailty with aging or in the presence of malignant disease.

The present study showed that, in male patients, those with a lower psoas muscle volume who underwent radical cystectomy had a longer hospitalization than those with a normal volume. In bladder cancer, there have been several studies regarding sarcopenia in patients undergoing radical cystectomy. Psutka et al. reported that, compared with non-sarcopenic patients, sarcopenic patients showed a significantly lower cancer-specific 5-year survival (49\% vs $72 \%$; $p=0.003)$ and OS (39\% vs. $70 \% ; p=0.003)$ [1]. Wan et al. showed that sarcopenia increased the risk of severe complications after radical cystectomy [20]. Smith et al. reported that sarcopenic female patients had an increased risk of post-operative complications compared with non-sarcopenic patients [21]. Consistent

Table 2 Postoperative complications (male patients only)

\begin{tabular}{llll}
\hline Clavien Grading Score & $\mathrm{PMI}<400$ & $\mathrm{PMI} \geq 400$ & $p$ value \\
\hline 0 & $7(17.1 \%)$ & $15(68.2 \%)$ & $<0.001$ \\
1 & $24(58.5 \%)$ & $6(27.3 \%)$ & \\
2 & $2(4.9 \%)$ & $1(4.5 \%)$ & \\
$\geq 3$ & $8(19.5 \%)$ & $0(0.0 \%)$ & \\
\hline
\end{tabular}

with these data, our results showed that a lower preoperative psoas muscle volume was associated with a prolonged hospitalization after radical cystectomy, suggesting that the psoas muscle volume might be a reliable factor for predicting a long hospitalization, presumably due to postoperative complications.

Most patients who undergo radical cystectomy for muscle-invasive bladder cancer are relatively old. Accordingly, predicting postoperative complications is important before performing radical cystectomy in such vulnerable patients. Thus far, combination therapy, including transurethral resection, systemic chemotherapy, and radiation therapy, have been thought to be the most effective bladder-preserving therapies, with a 5-year survival rate of around $50 \%$ to $60 \%$ [2, 22]. In patients over 70 years of age, intra-arterial systemic chemotherapy combined with radiation has been shown to be associated with a more favorable prognosis than radical cystectomy. Similarly, if radical cystectomy is contraindicated due to advanced age, sarcopenic patients may also be good candidates for bladder preservation.

According to the previous studies on the association of sarcopenia with the prognosis or postoperative complications, dual-energy X-ray absorptiometry and bioelectrical impedance analysis have been used to detect muscle volume. We used standard axial $\mathrm{CT}$ at the level of the umbilicus. A low psoas muscle volume detected by $\mathrm{CT}$ in this manner was associated with a longer post-operative admission due to postoperative complications. Our method is easy to perform, and in most patients undergoing radical cystectomy, no additional procedures for measuring the psoas muscle volume are required.

\section{Conclusion}

In the present study, we showed that sarcopenia is a predictor of longer hospitalization, and sarcopenic patients had a significantly worse OS than those without sarcopenia among male patients. The present findings support sarcopenia as a meaningful factor influencing the choice of therapy for locally advanced bladder cancer.

\section{Abbreviations}

OS: Overall survival; PMI: Psoas muscle index; SD: Standard deviation

\section{Acknowledgements}

We would like to thank R. Shimizu, Y. Nakamkura, and T. Yamaki for their technical assistance.

\section{Funding}

Grants from KAKENHI grants (16 K20152) from the Ministry of Education, Culture, Sports, Science and Technology of Japan.

Availability of data and materials

Due to ethical restrictions, the raw data underlying this paper are available upon request to the corresponding author. 


\section{Authors' contributions}

Conceived and designed the experiments: YS-M, TK, HU. Analyzed data: YS-M, TK, HI. Performed the experiments: YM ST DT KS YHay TM MO MN YHat JT YY KO KM NN MY HU. Wrote the paper: YS-M, TK. All authors read and approved the final manuscript.

\section{Ethics approval and consent to participate}

The present study was approved by the Institutional Review Board of Yokohama City University Medical Center [D1507018]. This was a retrospective study, and additional informed consent was not required by the IRB.

\section{Consent for publication}

Not applicable, in this study.

\section{Competing interests}

The authors declare that they have no competing interests.

\section{Publisher's Note}

Springer Nature remains neutral with regard to jurisdictional claims in published maps and institutional affiliations.

Received: 5 January 2017 Accepted: 13 September 2017

Published online: 18 September 2017

\section{References}

1. Psutka SP, Carrasco A, Schmit GD, Moynagh MR, Boorjian SA, Frank Stewart SB, Thapa P, Tarrell RF, Cheville JC, et al. Sarcopenia in patients with bladder cancer undergoing radical cystectomy: impact on cancer-specific and all-cause mortality. Cancer. 2014;120(18):2910-8.

2. Efstathiou JA, Spiegel DY, Shipley WU, Heney NM, Kaufman DS, Niemierko A, Coen JJ, Skowronski RY, Paly JJ, McGovern FJ, et al. Long-term outcomes of selective bladder preservation by combined-modality therapy for invasive bladder cancer: the MGH experience. Eur Urol. 2012;61(4):705-11.

3. Kawahara T, Furuya K, Nakamura M, Sakamaki K, Osaka K, Ito H, Ito Y, Izumi K, Ohtake S, Miyoshi Y, et al. Neutrophil-to-lymphocyte ratio is a prognostic marker in bladder cancer patients after radical cystectomy. BMC Cancer. 2016;16:185

4. Hautmann RE, de Petriconi RC, Pfeiffer C, Volkmer BG. Radical cystectomy for urothelial carcinoma of the bladder without neoadjuvant or adjuvant therapy: long-term results in 1100 patients. Eur Urol. 2012;61(5):1039-47.

5. Zahran MH, El-Hefnawy AS, Zidan EM, El-Bilsha MA, Taha DE, Ali-El-Dein B. Health-related quality of life after radical cystectomy and neobladder reconstruction in women: impact of voiding and continence status. Int J Urol. 2014;21(9):887-92.

6. Sejima T, Morizane S, Yao A, Isoyama T, Saito M, Amisaki T, Koumi T, Takenaka A. Prognostic impact of preoperative hematological disorders and a risk stratification model in bladder cancer patients treated with radical cystectomy. Int J Urol. 2014;21(1):52-7.

7. Ahmadi H, Montie JE, Weizer AZ, Morgan T, Montgomery JS, Lee CT. Patient Psoas muscle mass as a predictor of complications and survival after radical Cystectomy. Curr Urol Rep. 2015;16(11):79.

8. Cruz-Jentoft AJ, Baeyens JP, Bauer JM, Boirie Y, Cederholm T, Landi F, Martin FC, Michel JP, Rolland Y, Schneider SM, et al. Sarcopenia: European consensus on definition and diagnosis: report of the European working group on sarcopenia in older people. Age Ageing. 2010;39(4):412-23.

9. Kwon HJ, Ha YC, Park HM. The reference value of skeletal muscle mass index for defining the sarcopenia of women in Korea. J Bone Metab. 2015;22(2):71-5

10. Baumgartner RN, Koehler KM, Gallagher D, Romero L, Heymsfield SB, Ross RR, Garry PJ, Lindeman RD. Epidemiology of sarcopenia among the elderly in New Mexico. Am J Epidemiol. 1998;147(8):755-63.

11. Mir O, Coriat R, Blanchet B, Durand JP, Boudou-Rouquette P, Michels J, Ropert S, Vidal M, Pol S, Chaussade S, et al. Sarcopenia predicts early dose-limiting toxicities and pharmacokinetics of sorafenib in patients with hepatocellular carcinoma. PLoS One. 2012;7(5):e37563.

12. Del Fabbro E, Parsons $\mathrm{H}$, Warneke $\mathrm{CL}$, Pulivarthi $\mathrm{K}$, Litton JK, Dev R, Palla SL, Brewster A, Bruera E. The relationship between body composition and response to neoadjuvant chemotherapy in women with operable breast cancer. Oncologist. 2012;17(10):1240-5.
13. Sabel MS, Lee J, Cai S, Englesbe MJ, Holcombe S, Wang S. Sarcopenia as a prognostic factor among patients with stage III melanoma. Ann Surg Oncol. 2011;18(13):3579-85.

14. Demark-Wahnefried W, Kenyon AJ, Eberle P, Skye A, Kraus WE. Preventing sarcopenic obesity among breast cancer patients who receive adjuvant chemotherapy: results of a feasibility study. Clin Exerc Physiol. 2002;4(1):44-9.

15. Shiozu H, Higashijima M, Koga T. Association of sarcopenia with swallowing problems, related to nutrition and activities of daily living of elderly individuals. J Phys Ther Sci. 2015;27(2):393-6.

16. Tanimoto $Y$, Watanabe M, Sun W, Tanimoto K, Shishikura K, Sugiura $Y$, Kusabiraki T, Kono K. Association of sarcopenia with functional decline in community-dwelling elderly subjects in Japan. Geriatr Gerontol Int. 2013;13(4):958-63

17. Zhuang CL, Huang DD, Pang WY, Zhou CJ, Wang SL, Lou N, Ma LL, Yu Z, Shen X. Sarcopenia is an independent predictor of severe postoperative complications and long-term survival after radical Gastrectomy for gastric cancer: analysis from a large-scale cohort. Medicine (Baltimore). 2016;95(13):e3164.

18. Onesti JK, Wright GP, Kenning SE, Tierney MT, Davis AT, Doherty MG, Chung $\mathrm{MH}$. Sarcopenia and survival in patients undergoing pancreatic resection. Pancreatology. 2016;16(2):284-9.

19. Makary MA, Segev DL, Pronovost PJ, Syin D, Bandeen-Roche $K$, Patel $P$, Takenaga R, Devgan L, Holzmueller CG, Tian J, et al. Frailty as a predictor of surgical outcomes in older patients. J Am Coll Surg. 2010;210(6):901-8.

20. Wan F, Zhu Y, Gu C, Yao X, Shen Y, Dai B, Zhang S, Zhang H, Cheng J, Ye D. Lower skeletal muscle index and early complications in patients undergoing radical cystectomy for bladder cancer. World J Surg Oncol. 2014;12:14.

21. Smith AB, Deal AM, Yu H, Boyd B, Matthews J, Wallen EM, Pruthi RS, Woods ME Muss $\mathrm{H}$, Nielsen ME. Sarcopenia as a predictor of complications and survival following radical cystectomy. J Urol. 2014;191(6):1714-20.

22. Koga F, Kihara K. Selective bladder preservation with curative intent for muscle-invasive bladder cancer: a contemporary review. Int J Urol. 2012:19(5):388-401.

\section{Submit your next manuscript to BioMed Central and we will help you at every step:}

- We accept pre-submission inquiries

- Our selector tool helps you to find the most relevant journal

- We provide round the clock customer support

- Convenient online submission

- Thorough peer review

- Inclusion in PubMed and all major indexing services

- Maximum visibility for your research

Submit your manuscript at www.biomedcentral.com/submit
Biomed Central 